\title{
STUDY OF THE INNOVATIVE TRAINING MODULE "COMMUNICATION AND CUSTOMER SERVICE" IN A PIONEER TRAINING COURSE: "DIGITAL LITERACY FOR LABOUR MARKET"
}

\author{
M. Barbas ${ }^{1}$, P. Matos, ${ }^{2}$ A. Silva ${ }^{2}$ \\ ${ }^{1}$ Instituto Politécnico de Santarém - Escola Superior de Educação (PORTUGAL) \\ ${ }^{2}$ Higher School of Education of the Polytechnic Institute of Santarem (PORTUGAL) \\ mariapbarbas@gmail.com, pedro.matos@ese.ipsantarem.pt, ana.silva@ese.ipsantarem.pt
}

\begin{abstract}
This case-study researched disabled students' practices, experiences and transferable knowledge attained through a specific training module, communication, and customer service. The name of this innovative course is "Digital Literacy for Labour Market", which is a pilot training opportunity implemented in a HEI (Higher Education Institution). This type of initiative has already been implemented in other higher education institutions, such as the case of the Universidad Autonoma de Madrid, where a special programme for young students with intellectual disabilities, The Promentor Programme, was established. The aim of this project is the inclusion of people with intellectual disabilities in universities through several pedagogical and methodological processes (Gasset \& Herrero, 2016).
\end{abstract}

This paper presents the outcomes of students with intellectual disabilities who were included in an innovative and adapted learning environment, and were taught to develop soft and hard skills, namely key competencies related to communication, customer service and basic concepts of ICT (Information and Communication Technologies). In addition, this study exposes the views of the trainers, as well as other results and adopted best practices, in order to fully understand the students' learning curve.

Finally, concerning the methodological processes used to monitor this experience, a systematic approach was adopted, in which the following approaches were applied:

(i) representation of different social situations through role play techniques that allowed different communicative capacities to be put into practice;

(ii) customer or user service techniques adapted to the students' knowledge in order to understand different cases or scenarios;

(iii) strategies and techniques of communication adapted to the content to be presented to the students, with the purpose of including the characteristics of the receivers and ensuring efficiency in the communication processes.

In conclusion, further studies that adopt these types of learning experiences and specific target groups will need to adopt even more alternatives that understand and approach every pedagogical need that these learners may have.

Keywords: communication, customer service, learning modules, innovative curriculum design, new pedagogical and didactic practices.

\section{INTRODUCTION}

The importance to have key competencies such as digital literacy, soft and hard skills and basic knowledge in ICT's (Information and Communication Technologies) are fundamental aspects that any citizen, despite its gender, age or social background must have to actively address the digital challenges of nowadays society.

However, there are issues that need to be attained. One of them is the gap between those who are involved with the higher end of ICT's and technology in general by using and creating digital content and the other one are those identified in the "digital divide" as a group of people who are technologically excluded[1]. In order to understand this concept of "technologically excluded" and what it covers in terms of societal fields as well as for what groups of people include, it was developed the following diagram. 


\section{Digital Fields of exclusion}
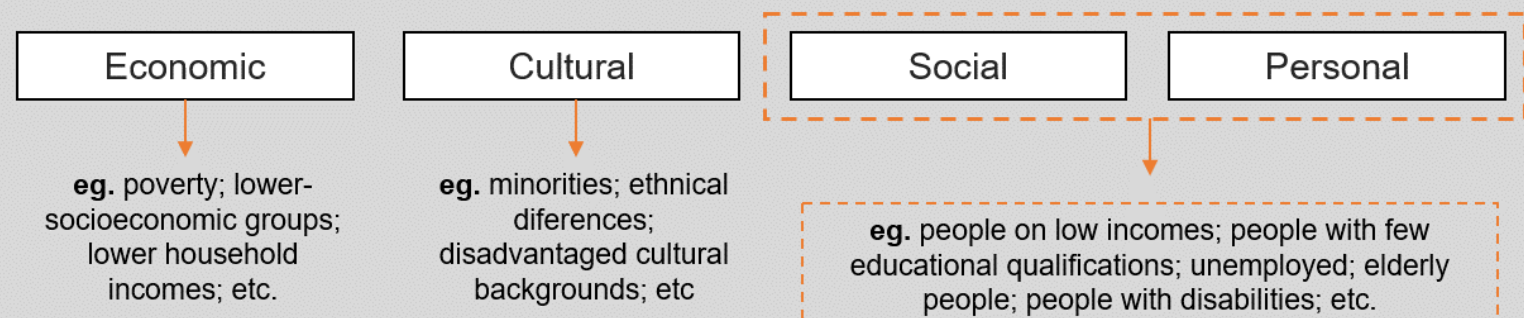

eg. people on low incomes; people with few educational qualifications; unemployed; elderly people; people with disabilities; etc.

Figure 1. Diagram of the digital fields of exclusion

This diagram was inspired by a previous developed model, focused on which fields, based by offline and digital levels, were impactful towards the digital exclusion[2]. These fields helped to guide the systematic process of this case study, specifically the highlighted ones, being these the social and personal fields. Thus, there is one parameter in which this research focused its study, analysis and benchmarks, that is, people with disabilities. Moreover, in this case study the focus group were higher education students with disabilities which enrolled in an innovative training programme about "Digital Literacy for Labour Market.

Concerning this focus group, students with disabilities, it is important to mention that these are prioritized targets across Europe, namely in the apprenticeship of digital skills and social and digital inclusion. According to the DIGCOMP: A Framework for Developing and Understanding Digital Competences in Europe aims, the development of training initiatives focused on main topics like (i) data and information literacy; (ii) cooperation and collaboration; (iii) digital content creation; (iv) safety and (vi) problem solving in which these topics are addresses by the respective training programme.

Moreover, according to recent statistics led by Eurostat showed that disabled people across Europe leave education and training earlier (31,5\%) compared with those not having a disability (12,3\%).[3]. Despite the situation not being so severe over the years, by presenting some reducing numbers, there are still issues that need a proper answer. This is due mostly because of the barriers that there are still being held. Mainly, the education sector still suffers from systemic and school-based problems in which there are several system-wide issues, such as:

a) Inadequate resources;

b) Lack of legislation, policy, targets and plans;

c) Inadequate training and support for students and teachers;

d) Inadequate Curriculum and Pedagogy

These are some of the several problems that the World Report on Disability[4] identifies as weaknesses that inclusive education must address promptly.

\section{STUDY OVERVIEW}

Despite all the initial framing, it is important to deconstruct the implemented case study and its research objectives. Initially, because the experience that was studied, observed, analysed and monitored had the following guidelines:

a) It started by the implementation of an innovative higher education training offer called "Digital Literacy for Labour Market", which is a unique course at national level (Portugal) for students with disabilities;

b) It conducted eleven students from different social, demographical and economic backgrounds in order to maintain a balanced focus group;

c) It was held at an innovative and adapted workspace/classroom in order to address their physical and emotional needs; 
d) It was a systematic approach that had the duration of five months with one class per week;

These were the broader aspects that shaped the implementation of this case study. As for the structural aspects, such as the choice of the curricula and the transferable knowledge that compounds areas like digital literacy, labour market, communication and costumer service, it is important to understand the concept of the training programme.

Therefore, the "Digital Literacy for Labour Market" training offer is aimed at young people with intellectual and developmental difficulties with a degree of incapacity equal to, or greater than $60 \%$. It is an innovative and supportive program, the most relevant feature of which is that it is the first model of inclusive education training in the context of higher education for intellectual disability in Portugal. This makes it a reference and training model for other experiences, the main characteristic being the personal development, well-being and social and labour inclusion within several working environments. It also adds the possibility of students engage in real life work experiences, such as internships in companies, city halls, hospitals, hotels, public bodies and other organizations.

As for the fundamental goals of the training course are to enable its students to be able to:

- Apply autonomously the concepts, theories and principles acquired in solving problems and decisions, in new work environments, or in unfamiliar environments;

- Acquire socio-labour commitments that foster growth as full citizens;

- Respond to demands and perform tasks appropriately with the combination of cognitive skills and practices, knowledge, motivation, values, attitudes and emotions;

- Acquire skills in the use of digital literacy that can effectively solve problems and perform tasks, using different tools in the work context;

- Acquire flexibility, understood as an ability to adapt to change and as a prelude to the critical capacity to analyse the work itself;

- Maintain enthusiasm for lifelong learning;

- Acquire the necessary training to compete for different offers (suitable for people with intellectual disabilities) in order to obtain employment in public administration agencies;

- Participate actively in the university environment, putting into practice a value system that promotes coexistence through satisfactory interpersonal relationships.

This said, the importance of this case study is, in first place, to research disabled students' practices, experiences and transferable knowledge attained through a specific training module, communication, and customer service. In second place, to present the outcomes of students with intellectual disabilities who were included in an innovative and adapted learning environment, and were taught to develop soft and hard skills, namely key competencies related to communication, customer service and basic concepts of ICT (Information and Communication Technologies). Finally, and very important is to understand the pluralism of the "Digital Literacy" concept since it allowed students to encode and decode several levels of learning, comprehension, interpretation and involvement with digital literacies[5].

Regarding the communication and costumer service areas, this study followed different approaches and methodologies focusing its research into: role play activities; communication basic concepts; customer service key techniques; alternative methods of communication; digital communication; personal development; among others. In addition, one of this study observations were that teaching and practicing communication skills with disabled students helped them to, individually, overcome their own physical, psychological or mental barriers despite their gender, age or level of incapacity[6] this training programme allowed them to, not only, receive information but to give feedback and become included towards the digital labour market.

Lastly, one important aspect to maintain is that this case study was conducted by a group of two teachers, two special needs tutors and three volunteers in order to, closely follow up each one of the eleven students with disabilities. This way, the students could be accompanied either in group or individually to clarify them of any doubt, worry or misplaced information. 


\section{METHODOLOGIES}

The methodologies are a key aspect of any conducted research. Responsible for guiding, outlining and monitoring all the processes of a specific case, study, hypothesis or object. In this case, the used methodologies followed a mixed perspective for either the researchers as well as the participants could choose different tools, so that they could apply the methods needed to plan, conduct and complete this case study.

Thus, it became possible to achieve two procedures for the study in question have become indispensable, i.e. a methodology focused on practice and another focused on the evaluation of the participants. For the expected results to be achieved, i.e. the analysis of a set of elements that made up in practice, the development of the study, the need to combine several methods was fundamental. For, in order to determine and monitor the aspects related to the research, observation and collection of non-deterministic data, the narrative factor, that is, qualitative, was necessary. This, in order to complement the various stages of the research. Then, to correspond to the collection of data related to statistical, numerical and tangible elements, the qualitative factor was also essential for the sampling and analysis of certain characteristics of the study.

In fact, this mixed methodology fits perfectly with the type of research carried out, since the combination of two types of methodological processes (quantitative and qualitative) allowed the integration of several specific methods. These are divided into diagrams, that is, elements that, after being analyzed, translate into numerical or statistical results, as well as techniques such as annotations and interventionist and non-interventionist observation, which fit into a more qualitative narrative. Along with this opportunity that only a mixed methodology can offer, there are still other reasons that led to the choice of this type of approach, since in addition to allowing a greater understanding of the various phenomena observable through research, it is responsible for integrating a more intuitive and practice.

It is with this sense to reinforce the reason that led to the choice of this type of methodology, that the mixed component is undoubtedly one of the key factors that allowed the design and development of this research, applying the correct and necessary procedures for each stage, manifestation or element to be studied / analyzed. This allowed us to move from a methodological perspective to a more strategic perspective, where the combination of multiple research techniques was crucial to determine certain aspects of the research. Especially when dealing with non-interfering methods that include documents, digital content created by participants or files analyzed, and another group that is responsible for the focus group process, specifically where methods such as evaluation matrices are found.

The evaluation methodology adopted in the Communication and Customer Service course followed a previously defined structure. This structure resulted from the Report-synthesis of consulting work: Design of an evaluation matrix of training in Digital Literacy for the Labor Market (2018-2020), developed by the Office of Psychological Intervention and Education (GIPE) and a team of teachers directly involved in training in Digital Literacy for the Labor Market. This evaluation methodology results from a systematic process that identifies, guides, interprets and reflects the different dimensions to be evaluated by the students. These dimensions of evaluation should preferably include three complementary aspects:

a) psychological assessment;

b) pedagogical-curricular evaluation;

c) organizational impact assessment.

Since it is a procedural assessment, it is important that data collection is dynamic and open to various instruments, with narrative and information-based registers based on information and communication technologies (for example, including digital presentations developed by students; certain digital applications, photographic and video recordings, etc.)

In short, the basis of this evaluation methodology is Al (action research) that allows a practical reflexivity (comprehensive, flexible and adaptive analysis) of the various actors that make up the students' evaluation process, giving a reconstructive position along of the results obtained.

Lastly, all the identified methodologies have a common aspect which is supporting the implementation of inclusive practices in the development of new assessment toolkits[12]. This approach tends to arrange a fair, reasonable and useful evaluation tool capable of avoiding previous fallbacks and 
generate a sustainable framework which compounds a flexible methodology for learning, teaching, practicing and helping any disabled student with his future into social, economic and technological contexts.

\section{RESULTS}

In terms of results this case study, due to its own methodology which is open, reflexive and dynamic in the sense that suffers from various interventions, was able to achieve several good practices that will be presented in the following sections. The first result was "the use of web 2.0. platforms for students with disabilities" that focused a more technologically driven aspects of this research. In this section it is well perceived that web 2.0. digital tools like Padlet or Zoom can be intuitive resources to improve student's digital literacy skills in various formats.

As for the second result, "development of digital content using ICT tool" it demonstrates the importance of information and communication technologies and how these can shape sustainable methods for disabled students learn, practice and improve their digital content creation know-how.

Concerning the third result, "alternative communication skills" it focused the implementation of several interactive methods that could improve and enhance communicative and customer service scenarios. In this case, the student's participation and effort were fundamental aspects for a good observation, study and analysis. As for the methods, these were mainly role play (based on personification) and phone service activities.

\subsection{The use of web 2.0 platforms for students with disabilities}

Web 2.0. platforms can be useful to change the socio-cultural context of students since it raises the opportunity of creating digital context or revolutionise new uses for already implemented technologies. Thus, the use of social bookmarking platforms such as wikis, blogs, social networks or other media sharing sites allows students to become more pedagogically apt since they can, by themselves, discover new ways of searching, publishing and sharing information[7]. Therefore, in this study the implied focus groups, students with disabilities, used two different web 2.0. platforms. The first one was Padlet, which is a multimedia platform that makes available a canvas to encourage creativity and the sharing of any type of content (image, videos, text, presentations, links, etc.). Mainly, it works like an infinite wall that can be used to encourage real-time, whole class participation and assessment[8]. In this case, this digital tool was used by the students as their dissemination channel in which they could share every one of their works. Most of all, they could publish, share and interact with all of their produced contact promoting a real time interactive experience. This experience was particular useful since it allowed them to develop their writing, communication and digital skills all in one specific place. In short, the use of Padlet by the students was analyzed and monitored following a structured process. This process consisted in:

a) a rating system based on several levels ( 1 to 5 ) to categorize what students did by using Padlet;

b) the most used options by students through Padlet;

This said, the students rated each one of these items with a satisfaction index based on pluses. In short, each plus represents a topic selection of one student.

Table 1. Example of the evaluation matrix for padlet

\begin{tabular}{l|c|c|c|c|c}
\hline \hline & $\begin{array}{c}\text { Level 1- } \\
\text { Less } \\
\text { Relevant }\end{array}$ & Level 2 & Level 3 & Level 4 & $\begin{array}{c}\text { Level 5- } \\
\text { Most } \\
\text { Relevant }\end{array}$ \\
\hline $\begin{array}{l}\text { Discussion } \\
\text { Forums }\end{array}$ & & & +++++ & $\begin{array}{c}++++ \\
+\end{array}$ & \\
\hline $\begin{array}{l}\text { Inspiration } \\
\text { Board }\end{array}$ & & & & ++ & $\begin{array}{c}++++++ \\
+++\end{array}$ \\
\hline
\end{tabular}




\begin{tabular}{l|l|l|l|l|l}
\hline \hline $\begin{array}{l}\text { Collecting } \\
\text { feedback }\end{array}$ & & $\begin{array}{c}+++++ \\
+\end{array}$ & ++++ & \\
\hline $\begin{array}{l}\text { Solo or group } \\
\text { presentations }\end{array}$ & & & & & $\begin{array}{c}++++++ \\
+++++\end{array}$ \\
\hline Portfolio & & & ++++++ & +++++ & \\
\hline \hline
\end{tabular}

Finally, after making a brief analysis of the evaluation matrix about the usage of padlet it is clear that:

- concerning the topics "inspiration boards" and "solo or group presentations" these were the most highlighted topics by the students. Since, it allowed them to be fully creative and with no boundaries to develop their own digital content.

- the second most important topics were "discussion forums" and "portfolio" which allowed them to explore their individuality as well as their communication skills;

- lastly, the topic with more starts in level 3 was collecting feedback which the students considered less important compared to the other ones.

Apart from the use of Padlet, it was also used another web 2.0. tool called ZOOM which is a software that allow communication through videoconference, online meetings, chat and mobile collaboration. This digital tool was used to improve their communication and customer service skills, in which they talked with each other through videoconference, simulating a client-customer conversation.

\subsection{Development of digital content using ICT tools}

The development of digital content using ICT tools was other result that this case study observed, achieved and deepen throughout a systematic approach. In this case, Information and Communication Technologies can be used to enhance exploratory, communicative and technological environments[9] through text processing digital applications or tools that allow the creation of interactive presentations. However, there are other perceived benefits that can be achieved with the use of ICTs such as:

- better communication skills

- improved assessment methods;

- better idea management;

Thus, the use of ICT tool was a best practice with a high added value since it allowed the students with disabilities to develop their digital literacy skills. It was clear in this case study's research that the students found these teaching a good method and strategy to learn and practice the ICT area. They felt certainty in what they were doing and despite their doubts or initial problems to become adapted to these new technologies their personal interests allowed them to further develop either the computer use as well as the ICT activity.

Lastly, other identified result was the importance of inclusive design and the fact that this area could relate to digital literacy, communication and customer service. Thanks to the students involvement and their experience through ICT it was clear that this type of work also needs to: a) include social context in the various technological experiences; b) facilitate even more the involvement of users with disabilities; c) support of requirements engineering methods to facilitate the elicitation of requirements from different user groups and d) the investigation of multimodality[10].

In short, using ICT tools to develop digital content and improve student's communication and customer service skills is a recurring good practice. However, there is still some refinement to do particularly concerned with the physical adaptation to most of the hardware used, such as: computers, peripherals and other, that sometimes may cause some type of discomfort on the students.

\subsection{Alternative communication skills}

Concerning alternative communication skills these were one of the most conclusive results that this case study research achieved. Since one of the aims of this training programme as well as of the case study was to improve and enhance the student's communication skills, regarding if it were oral, writing, digital or other. 
Therefore, this case study focused on understanding and introducing several examples of AAC (Augmentative and Alternative Communication) into training contexts. In this sense, AAC can be achieved through unaided systems like gestures, writing on paper, activating a speech-generating device (SGD), exchanging symbols[11] or using other medium to pass information.

This said, the developed researched outlined two AAC (Augmentative and Alternative Communication) methods:

- Roleplay activities;

- Phone service activities.

Concerning the roleplay activities, the students were involved in several exercises, such as: a) impersonation of different workstyles (e.g. lazy; active; busy; brilliant; leader; exaggerated; negative; positive; passive and know it all) through a cardboard with a representative image of the selected profession. This way, the students were able to practice and improve not only communication skills as well as their knowledge about the labour market. Other roleplay activity that the students were responsible to impersonate were the different type of professionals (doctor; farmer; professor; etc.). This method was interesting to observe since the students were using several skills to put in practice what they learned throughout the training programme in "Digital Literacy for Labour Market".

As for the phone service activities, the students were responsible for simulating phone calls to organizations, enterprises or other entities in order to implement the rules and aspects of being a good phone operator. The students were guided by a previously guidebook in which were all the guidelines (e.g. "Good afternoon Sir/Madam, how may I help you?") to initiate and conclude a successfully phone service with a client.

In short, studying, analysing and implementing these AAC methods with disabled student's was a challenging practice to take into action. However, it seems that Augmentative and Alternative Communication had a positive impact on improving student's social and labour skills due to the interactive aspects that compound with the used methods resulted in good experiences for the students

\section{CONCLUSIONS}

In a first phase of this case study it is possible to conclude that these type of training programmes are fundamental aspects for a more inclusive society. Not only disabled or disadvantaged students have the opportunity of becoming more educated as well as they acquire new social, professional and technological competencies to better face a more globalized labour market.

Secondly and concerning the implementation of the case study towards a focus group composed from eleven disabled students, it was possible to understand that subjects like digital literacy, communication and customer service are prioritized areas to successfully engage in labour contexts or social whereabouts.

Regarding the use of digital tools and technological approaches it was perceived that the students had a faster, flexible and more dynamic learning process. Not only was the student's adaptation towards the technological components fast and natural, the usage of collaboration, sharing and interaction platforms such as Padlet or Zoom, allowed that they would develop a variety of communicational, digital and social skills.

Concerning the alternative aspects that this study highlighted, such as role play and personifications activities, these allowed students to engage into different perspectives of learning. For these, could experience "real life" simulations of various type of workers, professions and other aspects regarding labour environments. As for the remaining AAC (Augmented and Alternative Communication) these potentialized the students learning curve, capacitating them with soft and hard skills useful for daily and work routines.

As for the evaluation frameworks specifically the one related to the usage of Padlet, it was possible to conclude that it was a best practice to have with the students. Not only they felt engaged in the process of choosing which topics or subjects they considered more relevant to produce or publish about, as well they had the opportunity to identify others and select them as optional or alternatives in the use of that digital platform. 
Finally, concerning difficulties or constraints that this study may had during its process, it was possible to identify the following:

- These type of training programmes are still a very small, practically none, practice at national level (Portugal);

- These experiences require an adapted and innovative workspace that can address all the needs of disabled students, either it's a physical, emotional or technological one.

- Concerning the curricula of the "communication and customer service" it had some considerable changes due to its original source, the Promentor programme, from the Universidad Autonoma de Madrid;

- The pedagogical contents available to students need to have the "Design for all" or Inclusive Design standards for accessibility. Since the Inclusive Design focus on moving away from special solutions and complex assistive devices towards increasing accessibility and inclusivity in mainstream design[13].

- The physical aspects like mobile devices or computers need to be perfectly adapted to the student's physical constraints;

- This type of training programmes requires a considerable large team in which is recommended to have a mix of technical competencies (teachers, tutors, volunteers and technicians).

In conclusion, further studies that adopt these types of learning experiences and specific target groups will need to adopt even more alternatives that understand and approach every pedagogical need that these learners may have.

\section{REFERENCES}

[1] R. Cullen, "Addressing the Digital Divide," Online information review, vol. 25, no. 5, pp. $311-$ 320, 2001.

[2] E. Helsper, "A corresponding fields model for the links between social and digital exclusion", Communication theory, vol. 22, no. 4, pp. 403 - 426., 2012.

[3] Eurostat, "Disability statistics - access to education and training", Eurostats statistics explained. 2014. Retrieved from https://ec.europa.eu/eurostat/statistics explained/index.php/Disability_statistics_-_access_to_education_and_training.

[4] A.A. Author, "Chapter Title" in Book Title (Editors eds.), pp.-pp., City/State: Publisher, Year of Publication.

[5] M. Knobel, "Digital Literacies: Concepts, policies and practices", vol. 30, Peter Lange, 2008.

[6] D. Hawkridge, T. Vincent, G. Hales, "New information technology in the education of disabled children and adults", Routledge Library Editions: Special Educational Needs, vol. 32, pp. 3-7., 2018.

[7] C. Mcloughlin, M. Lee, "Social software and participatory learning: Pedagogical choices with technology affordances in the Web 2.0 era", Proceedings ascilite Singapore, pp. 664-669.

[8] B. Fuchs, "The writing is on the wall: using Padlet for whole-class engagement", LOEX Quarterly, vol. 40, no. 4, pp. 7-9, 2014.

[9] P. Williams, H.R, Jamali, D. Nicholas, "Using ICT with people with special education needs: what the literature tells us." Aslib Proceedings, vol. 58, no. 4, pp. 330-345, 2006

[10] T.H. Røssvoll, K.S. Fuglerud, "Best practice for efficient development of inclusive ict", International Conference on Universal Access in Human-Computer Interaction, pp. 97-106, 2013

[11] J.B. Ganz, T.L. Earless-Vollrath, A.K. Heath, R.I., Parker, M.J. Rispoli, J.B. Duran, "A metaanalysis of single case research studies on aided augmentative and alternative communication systems with individuals with autism spectrum disorders", Journal of autism and developmental disorders, vol. 42, no. 1, pp. 60-74, 2012 
[12] M. Adams, S. Brown, Towards inclusive learning in higher education: Developing curricula for disabled students, Abingdon, Oxon: Routledge, 2006

[13] P.J. Clarkson, R. Coleman, S. Keates, C. Lebbon, Inclusive design: Design for the whole population. London: Springer-Verlang London Limited, 2013 